The Federal Reserve Bank of Kansas City ECONOMIC RESEARCH DEPARTMENT

\title{
Global Inflation Dynamics
}

Craig Hakkio

January 2009

RWP 09-01 


\title{
Global Inflation Dynamics
}

\author{
Craig S. Hakkio* \\ Federal Reserve Bank of Kansas City
}

January 9, 2009

RWP 09-01

\begin{abstract}
This paper examines the dynamics of various measures of national, regional, and global inflation. The paper calculates the first two common factors for four measures of industrial country inflation rates: total CPI, core CPI, cyclical total CPI, and cyclical core CPI. The paper then demonstrates that the first common factor is sometimes helpful in forecasting national inflation rates. It also shows that the second common factor and the first common factor for cyclical inflation is sometimes helpful in forecasting national CPI inflation rates. Finally, the paper suggests that the commonality of industrial inflation rates reflects the commonality of the determinants of inflation.
\end{abstract}

JEL Classification: E31, E32, E37

Keywords: Inflation, common factor, global inflation, industrial countries.

${ }^{*}$ Economic Research Department, 1 Memorial Drive Kansas City, Missouri 64198. Telephone: (816) 881-2456. Fax: (816) 881-2199. Email: craig.s.hakkio@kc.frb.org. The author thanks John Seliski for helpful research assistance and Roberto Billi, Todd Clark, Troy Davig, George Kahn, Ed Knotek and members of the Federal Reserve Bank of Kansas City Seminar for helpful comments. The views expressed in this paper are those of the author and do not necessarily reflect the views of the Federal Reserve Bank of Kansas City or the Federal Reserve System. 


\section{Introduction}

It is well known that inflation rates around the world have been falling over the last few decades (see, for example, Rogoff (2003)). Inflation in the industrial economies began declining in the early 1980s while inflation in the emerging economies began declining in the 1990s. For much of this century, though, global inflation has been relatively stable. For example, world inflation (as measured by the IMF) averaged 3.8 percent and ranged between 3.0 and 5.4 percent while industrial country inflation (again as measured by the IMF) averaged 2.1 percent and ranged between 1.3 and 3.3 percent. Some of the large range of outcomes reflects energy prices since core inflation for OECD countries excluding the high inflation countries (as measured by the OECD) averaged 1.9 percent and ranged between 1.4 and 2.3 percent. Finally, there has been an increase in global inflation (for the world and any regional grouping) since early 2007. While energy prices may partly reflect this increase, they are not the whole story since core inflation for the G7 and OECD countries excluding the high inflation countries (as measured by the OECD) began increasing in 2006.

This paper examines the dynamics of various measures of national, regional, and global inflation. Several authors have studied inflation rates in an international setting. For example, Corvoisier and Mojon (2004) identify 2 or 3 breaks in mean inflation rates in most OECD countries. Since the breaks tend to be associated with breaks in nominal variables rather than real variables, they conclude that the breaks reflect monetary phenomenon. In addition, Levin and Piger (2004) study inflation dynamics of industrial countries and also identify a break in the mean inflation rate. Once they incorporate the mean break, they find that inflation rates exhibit relatively low inflation persistence. The study by Ciccarelli and Mojon (2005) is closest to this paper. They also study OECD inflation rates and calculate a measure of global inflation as the first common factor among OECD inflation rates. They show that forecasts of national inflation rates that include their measure of global inflation outperform univariate measures of inflation. This paper also estimates the first common factor among OECD inflation rates (using principal components), but expands the set of inflation rates to include overall CPI inflation, cyclical CPI inflation, core CPI inflation, and cyclical core CPI inflation. This paper also studies whether the first common factor helps forecast these four measures of inflation. In addition, this paper studies whether including the second common factor and including the first common factor for cyclical inflation helps to predict overall CPI inflation.

This paper is organized as follows. Section 2 of the paper calculates the first two common factors using principal components for four measures of industrial country inflation rates: total CPI, core CPI, cyclical total CPI, and cyclical core CPI. Section 3 then studies the relationship between the first common factor and industrial and non-industrial inflation rates. It shows that the first common factor is useful in explaining U.S. inflation rates, other industrial country inflation rates, and non-industrial country inflation rates. The section also shows that the second through 
fourth common factors are useful in explaining U.S. and other industrial country inflation rates. Finally, section 4 of the paper speculates on the source of commonality among industrial country inflation rates.

\section{Common Factors in Industrial Inflation}

This section discusses the calculation of the first two common factors in industrial country inflation rates. Four measures of inflation are used: total CPI inflation, core CPI inflation, cyclical total CPI inflation, and cyclical core CPI inflation.

\subsection{Data}

The OECD and IMF are the two basic sources for data. The OECD dataset includes data for 30 OECD countries and 6 non-OECD countries (Brazil, China, India, Indonesia, Russian Federation, and South Africa) from 1960q1 - 2008q1. Not surprisingly, not all countries have data for all observations. In order to focus on more than just these countries, an IMF dataset is also used; it includes inflation rates for various regions of the world: world, industrial countries, Euro area, developing countries in Europe, western hemisphere, non-oil developing countries, emerging and developing economies, the middle east, developing Asia, Africa, and oil exporting countries.

To maximize the length of the sample period, 19 countries are used for overall CPI inflation from 1961 - 2008q2. ${ }^{1}$ However, the set of OECD countries that provide core inflation rates is more limited than those that provide overall inflation. In order to maximize the number of countries used, Korea is dropped from the sample and the sample period is 1980q1-2008q1 for 18 countries. Finally, cyclical inflation is calculated using a Hodrick-Prescott filter.

Charts 1A - 1D show inflation rates for various regions. It is clear from the charts that the global economy has seen a wide range of inflation rates. In particular, inflation was 1100 percent in Poland in 1990q1 and was about 6000 in Brazil in 1990q2.

While there are many measures of "global" inflation, this paper will use a measure based on OECD countries for a couple reasons. First, the OECD database appears to be more reliable than the IMF database. And as noted earlier, the OECD database focuses on OECD countries which are mainly industrialized and 6 non-member countries. In addition, it appears as though U.S. inflation is more closely related to the inflation in the industrialized countries than in emerging economies. However, rather than use the inflation rates from all 30 current members, this paper excludes 11 countries that had high inflation rates or are missing several years of data. By excluding several countries, the sample size can run from 1960q1 to $2008 \mathrm{q} 1$.

\footnotetext{
${ }^{1}$ The countries are Australia, Austria, Belgium, Canada, Finland, France, Germany, Italy, Japan, Korea, Luxembourg, Netherlands, New Zealand, Norway, Spain, Sweden, Switzerland, the United Kingdom, and the United States.
} 

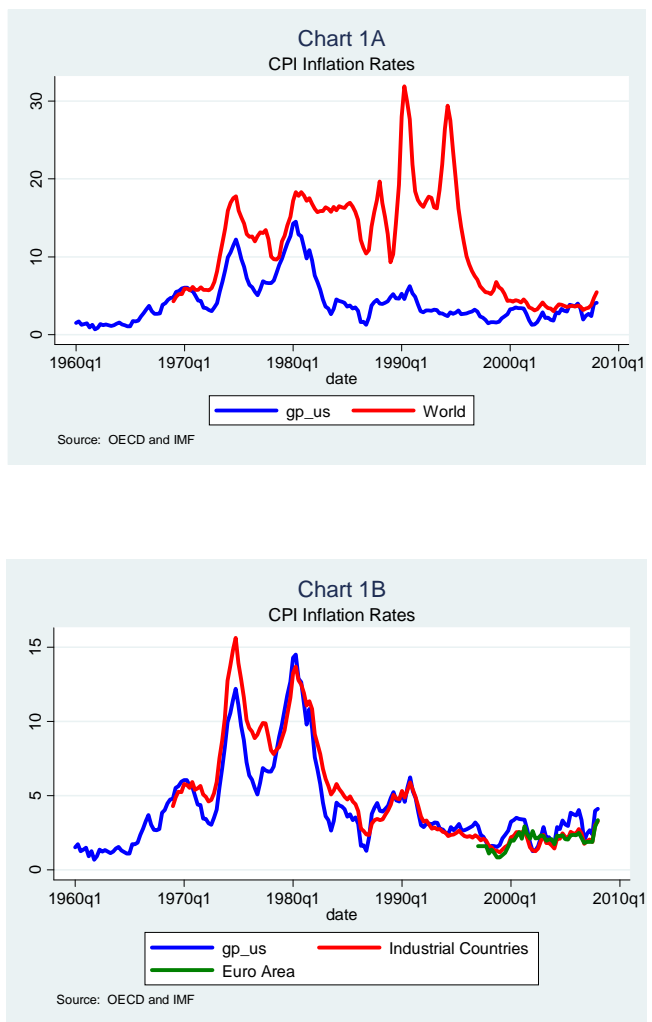

\subsection{A common factor model for national inflation rates}

In this paper, it is assumed that each national inflation rate can be written as a linear combination of 2 common factors and 1 unique factor:

$$
\pi_{t}^{i}=\lambda_{1}^{i} f_{1, t}+\lambda_{2}^{i} f_{2, t}+\varepsilon_{t}^{i}
$$

where $\pi_{t}^{i}$ be country i's inflation rate at time $\mathrm{t}$ and $f_{i, t}$ is the $\mathrm{i}$-th common factor. Given this specification, the first common factor would be interpreted as an estimate of industrial inflation. ${ }^{2} 3$ The factors are estimated by principal components. ${ }^{45}$ The first common factor estimated by principal

\footnotetext{
${ }^{2}$ Ciccarelli and Mojon (2005) conduct a similar analysis in measuring "global inflation" as the first common factor. In their paper, they find that the results using static factor analysis are essentially the same as using dynamic factor analysis. In this paper, we use principal components to estimate the factor model.

${ }^{3}$ Kim and Mueller (1978) provide a good introduction to factor analysis.

${ }^{4}$ The estimation is done using Stata, Version 10 by specifying the "factor" command and the "pcf" option.

${ }^{5}$ Theil (1971) provides an excellent overview of principal components. Other references are Jackson (2003) and Jolliffe (2004).
} 

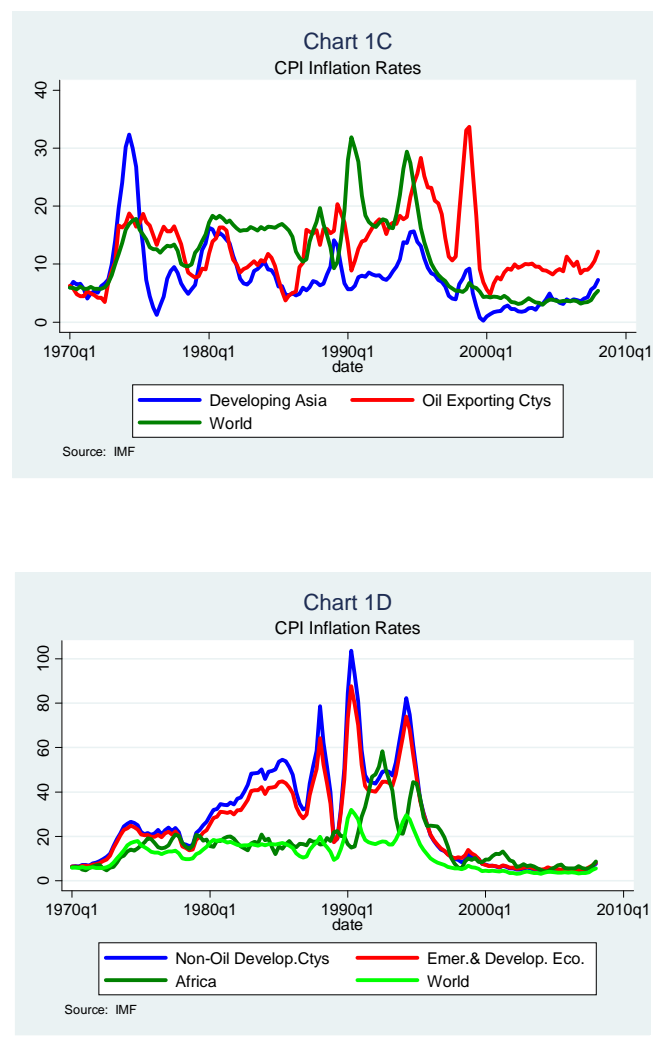

components and the first common factor estimated by factor analysis are highly correlated. ${ }^{67}$

The estimation results are displayed in Tables $1-4$. The first 2 columns show the factor loadings associated with the first two factors $\left(\lambda_{j}^{i}, \mathrm{i}=1, \ldots, 19\right.$ countries and $\mathrm{j}=1,2$ factors. Most of the coefficients for the first factor are similar, with Korea and Switzerland smaller than the others. The coefficients for the second principal component are half negative and half positive. As summary statistics, the last 4 rows of the table show the average, standard deviation, minimum, and maximum for each column variable. The third and fourth columns of the table show the mean and standard deviation of the national inflation rates. In general, the coefficients for the second common factor are negative for high mean inflation countries and positive for low inflation countries. Given the formula for the common factors, this is not too surprising. The next two columns provide some information on how well the first factor summarizes the data. The first factor obviously does not explain all the variance of each national inflation rate. The column labeled "Uniqueness" gives the fraction of variance for the variable that is not explained by the first factor. The average value is 20 percent (shown in the row labeled "avg"), and ranges between

\footnotetext{
${ }^{6}$ As discussed in Jolliffee (2004, pages 158 - 161), both factor analysis and principal component analysis focus on the covariance or correlation matrix. Principal component analysis concentrates on the diagonal elements while common factor analysis concentrates on the off-diagonal elements.

${ }^{7}$ When estimated over the same sample period, the correlation between estimating the first common factor by principal components and by factor analysis was 0.9995 ; the correlation for the second common factor was 0.9942 .
} 


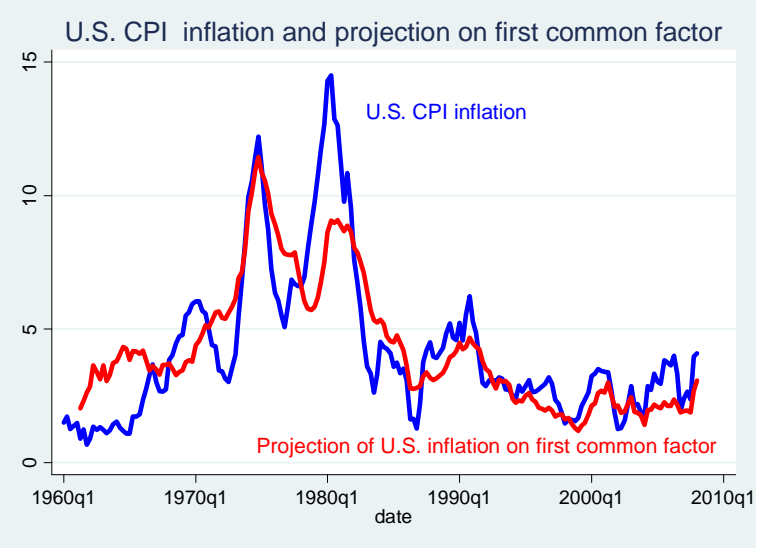

10 percent and 53 percent (Korean inflation). The row labeled "R2" is the $\mathrm{R}^{2}$ from a regression of the national inflation rate (actual inflation rate, not normalized inflation rate) against the first common factor. Thus, it is a measure of the explanatory power of the first principal component for each national inflation rate. On average, the $\mathrm{R}^{2}$ is 0.71 and ranges between 0.41 and 0.88 . Finally, the last column shows the results of the Kaiser-Meyer-Olkin of sampling variability. "kmo" takes a value between 0 and 1.0, with small values indicating that the variables have too little in common to warrant a principal component analysis. The overall kmo statistic, shown in the row labeled "avg", is 0.92. A value between 0.90 and 1.0 is generally described as "marvelous." 8

Chart 2 plots the U.S. inflation and the projection of the U.S. inflation on the first common factor. Thus, the red line shows the predicted value of U.S. inflation based on the first common factor. The chart shows visually that the first common factor is highly correlated with U.S. inflation.

We next turn to estimating a common factor model (using principal components) for cyclical inflation. Cyclical inflation is calculated by first using a Hodrick-Prescott filter to estimate trend inflation and then subtracting trend inflation from actual inflation. There are a couple reasons for estimating a factor model using cyclical inflation. One reason is that the common factor just calculated used the actual inflation rate as opposed to the change in inflation. ${ }^{9}$ So, rather than capturing the trend using a first difference, this paper captures the trend by using a HodrickPrescott filter. Another reason is that Dahl, Hansen, and Smidt (2008) show that they can improve the out-of-sample forecasting of factor models by estimating a factor model for the pure cyclical component of the series. Rather than using the Hodrick-Prescott trend on the national inflation rate, we could have used the common factor from the model estimated using actual inflation. The two estimates of cyclical inflation are similar but contain different information (the correlation coefficient is 0.68$)$.

\footnotetext{
${ }^{8}$ See Stata, version 10, Multivariate Statistics, page 522.

${ }^{9}$ Ciccarelli and Mojon (2005) also estimate a common factor using actual inflation rates. In contrast, Stock and Watson (2002) estimate a model using the first difference in inflation, but note that Stock and Watson (1999) found little difference between an $\mathrm{I}(1)$ and an $\mathrm{I}(2)$ factor model.
} 
The results for cyclical inflation are shown in Table 2. Not surprisingly, the results are similar, but weaker, than those in Table 1 . The loading factors (for the first factor) are smaller than in Table 1, averaging 0.589 for cyclical inflation versus 0.837 for national inflation. In addition, the "uniqueness" is much larger, 54 percent versus 20 percent for overall CPI inflation. The $\mathrm{R}^{2}$ is also smaller, averaging 0.376 (versus 0.708). Finally, the kmo statistic is less supportive of principal component analysis for cyclical inflation. The overall value is 0.819 , which is said to be "meritorious."

The results for core CPI inflation are shown in Table 3. Here, the results are similar to those for overall CPI inflation (shown in Table 1). Again, the factor loadings are similar in magnitude. (Recall that Korea is excluded from the analysis for core CPI inflation.) The average uniqueness is slightly less ( 17 percent for core CPI versus 20 percent for overall inflation). The $\mathrm{R}^{2}$ for a regression of each core inflation rate on the first factor ranges 0.53 to 0.95 , with an average of 0.75 . Finally, the kmo statistic for overall fit is 0.892 , at the high end of "meritorious" and almost equal to the low end of "marvelous."

Finally, the results for cyclical core CPI inflation are shown in Table 4. As was true for cyclical inflation, the $\mathrm{R}^{2}$ for a regression of each cyclical core inflation rate on the first factor ranges between 0.00 and 0.56 , with an average of 0.25 . The kmo statistic for overall fit is 0.63 , which is considered "mediocre."

\section{Industrial Inflation and National Inflation Rates}

The previous results show that the first factor is highly correlated with national inflation rates-as shown by relatively high $\mathrm{R}^{2}$ in a regression of each national inflation on the first factor. Since the first factor is based on national inflation rates, it is perhaps not surprising that it is contemporaneously correlated with national inflation rates. This section studies the dynamic relationship between national inflation rates and the common factors of industrial country inflation rates.

\subsection{An Error Correction Model for National and Regional Inflation Rates}

Beyond contemporaneous correlation, the first factor is also helpful in predicting inflation. In particular, the first common factor is an "attractor" for national inflation rates, as seen by considering an error correction model (ECM) for national inflation rates (overall and core, actual and cyclical) and the first factor (denoted F). Specifically, assume that $\pi_{t}^{i}$ and $\mathrm{F}_{t}$ are cointegrated. Then, the first differences can be written as follows:

$$
\begin{aligned}
\Delta \pi_{t} & =\beta_{10}+\beta_{11} \Delta \pi_{t-1}+\ldots+\beta_{1 p} \Delta \pi_{t-p}+\gamma_{11} \Delta F_{t-1}+\ldots+\gamma_{1 p} \Delta F_{t-p}+\alpha_{1}\left(\pi_{t-1}-\lambda_{0}-\lambda_{1} F_{t-1}\right)+u_{1 t} \\
\Delta F_{t} & =\beta_{20}+\beta_{21} \Delta \pi_{t-1}+\ldots+\beta_{2 p} \Delta \pi_{t-p}+\gamma_{21} \Delta F_{t-1}+\ldots+\gamma_{2 p} \Delta F_{t-p}+\alpha_{2}\left(\pi_{t-1}-\lambda_{0}-\lambda_{1} F_{t-1}\right)+u_{2 t}
\end{aligned}
$$

The error-correction term $\left(\pi_{t}-\lambda_{0}-\lambda_{1} F_{t}\right)$ helps to predict future values of $\Delta \pi_{t}$ and $\Delta F_{t}$.

The results for the error-correction term are shown in Tables 5 - 8. The coefficients are shown in the columns labeled "alpha," "lambda1," and "lambdo0" and the t-statistics are shown in the 
columns labeled "t-alpha" and "t-lambda1." Looking at Tables 5 - 8 as a group, in all but three cases $\alpha_{1}<0$. The three exceptions are Switzerland for cyclical CPI inflation, the United Kingdom for core CPI inflation, and Austria for cyclical core CPI inflation; in these cases $\alpha_{1}$ is positive but insignificant. In addition, in all but 11 cases, $\alpha_{1}<0$ and significant. These results suggest that when a national inflation rate is greater than the global inflation rate $\left(\mathrm{F}_{t}\right)$, the national inflation rate tends to decline next period.

In addition, the first factor for industrial inflation rates is helpful in explaining the dynamics of other national and regional inflation rates. To do this, we estimate an ECM for total CPI inflation in Brazil, India, Indonesia, and the Russian Federation, and for IMF regional inflation rates for industrialized countries, euro area, developing countries in Europe, western hemisphere, nonoil developing countries, emerging market developing countries, the middle East, developing Asia, Africa, and OPEC. The results are shown in Table 9. In most cases, $\alpha_{1}<0$ and significant. The exceptions are: industrial countries (negative and insignificant), Euro area (positive but insignificant), nonoil developing countries (positive and significant), emerging developing economies (positive but insignificant), and Africa (negative and insignificant). These results suggest that non-industrial country inflation rates also move toward the first principal component of national industrial country inflation rates.

\subsection{The Importance of the first common factor in predicting U.S. inflation}

This subsection shows that the first common factor for industrial inflation rates is important for understanding inflation dynamics in the U.S. In particular, global (industrial) inflation-as measured by the first factor-helps forecast U.S. inflation. While it is generally difficult to forecast inflation, an ECM with global inflation appears to do a good job in forecasting U.S. inflation. In this section, we again estimate and forecast several models for 4 measures of U.S. inflation: CPI inflation, cyclical CPI inflation, core CPI inflation, and cyclical core CPI inflation.

To show the importance of global (industrial) inflation as measured by the first factor, we consider two models for U.S. inflation that include the first factor and then compare the results to 4 univariate models (that do not include the first common factor). For all 6 models, we first estimate the model over 1960q1 - 1989q4 and dynamically forecast inflation 1, 4, and 8 quarters ahead. In estimating the models with the common factor, we estimate the common factor based on data available at the time. We then update the sample and estimate over 1960q1 - 1990q1 (including estimating a new factor) and dynamically forecast 1, 4, and 8 quarters ahead. We continue updating the sample period, with the last sample period being 1960q1 - 2006q1. Since core inflation is available for a shorter sample, we begin by estimating the model over 1980q1 1999q4, using 20 years of data rather than 30 years of data.

The two models that include the first common factor are an ECM and a 2-variable VAR. The ECM is the same as used in the previous section and the VAR includes the first common factor and U.S. inflation. For each sample period, we calculate the first common factor using data only for that sample period. In estimating the VAR, we use the AIC to calculate the number of lag for each sample period. 
The results are shown in Tables 10 - 13. The table shows the RMSE for all 6 models, along with the RMSE for the 4 univariate models relative to the ECM and VAR models that employ the first common factor. A relative RMSE $>1$ indicates that the ECM or VAR does better (in terms of RMSE) than the other forecast. The results are generally encouraging. In most cases, the models that include the first common factor do better (in terms of RMSE) than the univariate models that do not include the first common factor. In particular, the ECM and VAR with the first common factor beats the random walk (and random walk with drift) for total CPI inflation at 1 and 8 steps ahead; for cyclical total inflation at 1, 4, and 8 steps ahead; for core inflation at 1 step ahead (and at 1, 4, and 8 steps ahead when comparing to a random walk with drift); and for cyclical core inflation at 1, 4, and 8 steps ahead. The cases where the ECM or VAR is beaten by one of the models are:

1. CPI inflation, 4-steps ahead, all 4 univariate models

2. Cyclical CPI inflation, 4-steps ahead, AR(2) model

3. Core CPI inflation, 4-steps and 8-steps ahead, AR(2) and Random Walk models

4. Cyclical core CPI inflation, 4-steps and 8-steps ahead, $\mathrm{AR}(2)$ relative to the ECM.

\subsection{The importance of the first common factor in explaining other national inflation}

We can also compare the forecasts for national inflation rates with and without the first common factor. Similar to the last section, we estimate two benchmark models for national inflation using the first common factor-an ECM and a 2-variable VAR. We then compare these results to model forecasts from the same 4 univariate models. Since there are 18 "other" inflation rates, showing all of the results would require 18 tables for overall CPI inflation, 18 for cyclical inflation, 17 for core inflation, and 17 for cyclical core inflation (remember that Korea is excluded from the sample of countries using core CPI inflation). Therefore, Tables 14 - 17 summarize the results for each measure of inflation. Each table simply answers the following question: "How many univariate models beat the ECM and VAR (which use the first factor)?" For each element of the table, the maximum possible value is 4, indicating that all models beat the ECM or VAR; the smallest possible value is 0 indicating that no model beats the ECM or VAR. Thus, small values are supportive of using the first common factor.

Given the large number of results, it is difficult to come to firm conclusions. In general, though, including the first factor in forecasting models for CPI inflation (Table 14) is very helpful for Australia, Canada, and Sweden (since there are relatively few univariate models that beat models including the first factor). For cyclical inflation (Table 15), including the first factor is also very helpful for Australia, Canada, Netherlands, New Zealand, Sweden, and the United States. Turning next to core inflation (Table 16), including the first factor is very helpful only for Austria. However, the results are stronger for cyclical core inflation (Table 17). In this case, including the first factor is helpful for Canada, France, Germany, Norway, and the United States. 
We next turn to whether the first factor for cyclical inflation helps to forecast the national overall inflation rate. Specifically, we consider an ECM and VAR model that includes the first factor for overall CPI inflation and the first factor for cyclical CPI inflation. Since the first factor for overall inflation could be picking up changes in trend inflation, it might help to include the first factor for cyclical (detrended) inflation. As suggested by Dahl, Hansen, and Smidt (2008), "Monte Carlo simulations suggest that the modification may actually improve the forecast performance of the factor model when the variances of the irregular components are large while the number of time series in the factor model is relatively small."

The results are shown in Table 18, which answers the question: "Does adding the first factor for cyclical inflation to a model that includes the first factor for inflation help forecast national inflation rates?" To ease the reading of the table, only "Y" is indicated; a blank cell means the first factor for cyclical inflation does not help forecast national inflation. In this case, we estimate rolling regressions to forecast overall inflation 1, 4, and 8 steps ahead. For each sample period, we calculate the first factor for overall inflation and the first factor for cyclical inflation. In addition, for each sample period, we calculate an estimate of cyclical inflation. In this way, the results are close to "real time forecasting." (The only difference is that we use final data and not data that was actually available to researchers.) If the RMSE for the model with the first factor for cyclical inflation and the first factor for overall inflation is less than the RMSE for a model with the first factor for overall inflation, then we conclude that the answer is "yes"-adding the first factor for cyclical inflation helps to forecast overall inflation. Adding the first common factor for cyclical inflation helps predict CPI inflation in half of the cases (57 out of 114 cells have a "Y"). In particular, the greatest improvement comes for Finland, Korea, Netherlands, New Zealand, and Norway (since "Y" appears in 5 or 6 of the columns in those rows).

Table 19 answers a similar question: Does adding the second common factor for national inflation (to an equation with the first common factor) help to forecast national inflation rates?" In this case, the second common factor helps forecast national inflation in one quarter of the cases (28 of 114 cells have a "Y"). There does not seem to be any strong connection between whether the second common factor helps predict and whether the first common factor for cyclical inflation helps predict national inflation rates. For example, in 20 of the 28 cases in which the second common factor helps forecast national inflation, the first common factor for cyclical inflation also helps predict national inflation rates. However, there are many cases in which the first common factor for cyclical inflation helps predict national inflation but the second common factor does not help.

\subsection{The importance of additional common factors in explaining overall CPI inflation}

As was clear in Tables 1 - 4, for many countries more than the first common factor were important. In this section, we examine whether lagged values of the first 4 common factors are helpful in explaining national inflation rates. Specifically, we regress each national inflation rate against lags 1 - 4, lags $4-7$, and lags 8 - 11 of the national inflation rate and 4 common factors: 


$$
\pi_{t}=A(L) \pi_{t-K}+B^{1}(L) f_{t-K}^{1}+B^{2}(L) f_{t-K}^{2}+\ldots+B^{4}(L) f_{t-K}^{4}+u_{t}
$$

where $\mathrm{A}(\mathrm{L})$ and $\mathrm{B}^{i}(\mathrm{~L})$ are 4 th order lag polynomials and $\mathrm{K}=1,4,8$.

Tables (20) - (22) summarize the results. Rather than presenting all of the details, the table simply records the t-statistic for whether the sum of the lag coefficients on $\pi, f^{1}, f^{2}, f^{3}, f^{4}$ are significantly different from zero. In general, the results indicate that the lagged values of the 4 common factors are quite helpful in explaining national inflation rates for 1-step, 4-steps, and 8steps ahead. Looking at the importance of the lagged common factors for national inflation rates, it is generally the case that lags of $f^{1}$ are important for more countries than are lags of $f^{2}$, which are important for more countries than are lags of $f^{3}$, which are important for more countries than are lags of, $f^{4}$.

Tables (23) - (25) consider a similar exercise for other regional inflation rates along with food and energy price inflation. Once again, lags of the first four common factors are generally important in explaining non-industrial national and regional inflation rates and food and energy inflation 1.

\section{The Commonality of Industrial Inflation Rates}

Previous sections have identified a common factor in industrial inflation rates (overall and core, actual and cyclical) and have shown that the first common factor helps predict industrial inflation rates and that the first four common factors are also helpful in explaining overall CPI inflation in industrial economies and non-industrial economies, and regional inflation rates, and in food and energy prices. This section examines possible reasons for the commonality of industrial inflation rates.

An obvious explanation is globalization. A number of papers have examined whether globalization has changed the level or dynamics of national inflation rates. For example, Borio and Filardo (2007) show that proxies for global economic slack are significant in traditional inflation rate equations. In addition, Ball (2006) argues that globalization has not changed the dynamics of inflation. While interesting, the results are not directly relevant for the question posed in this section: why does a common factor in national inflation rates exist? However, the paper by Ciccarelli and Mojon (2005) does show that their measure of global inflation responds to commodity prices, global real economic activity, and global monetary variables. While a common monetary policy strategy of low and stable inflation may play a role in explaining the decline in global inflation rates, it is unlikely to explain why there is commonality among cyclical inflation rates. For this paper, if there is a common factor among the determinants of national inflation rates, or if the shocks to national inflation rates are correlated, then one would expect to find a common factor among national inflation rates. What matters for this paper is whether there is a commonality among determinants or shocks, and not necessarily whether the commonality has increased.

We now provide some evidence on the commonality of some of the business cycle shocks across industrial economies. If all industrial economies are hit with the same shock, or highly correlated shocks, then it is likely that cyclical inflation rates will be correlated. In order to see this, cyclical 
measures of unemployment and real GDP are constructed using a Hodrick-Prescott measure of trend. In addition, other determinants of inflation are considered: real GDP growth, narrow money growth, broad money growth, a short-term interest rate, an intermediate term interest rate, and a long-term interest rate. Since not all industrial countries have observations for all of these variables, the number of countries used is limited. We next calculate the first three common factors for each variable. The first common factor provides an estimate of the common trend in each variable. The first common factor for cyclical unemployment, for example, can be thought of as global cyclical unemployment.

To measure commonality, this paper shows a measure of "Uniqueness" for the first common factor and the first three common factors. As discussed earlier, "uniqueness" shows the proportion of variance of the variable that is not explained by the common factors. Table 26 shows these proportions in the columns labeled "1 factor" and "3 factors." A small value of uniqueness suggests that the common factor explains a lot of the variance. Since a large value of uniqueness suggests that the common factor does not explain much of the variance, the table shows the average value of uniqueness and the maximum value of uniqueness. The column labeled "Number of countries" shows the number of countries used in calculating the common factor. The table suggests that there is generally a great deal of commonality among countries for each determinant of inflation that is considered. One clear exception is narrow money growth because the uniqueness is quite high- 0.71 for one common factor. However, excluding narrow money growth, the uniqueness ranges from 0.03 to 0.58 (for cyclical unemployment). For all other variables, the average uniqueness for 3 factors is less than 0.33 meaning that the first 3 common factors explain about two-thirds of the variance of the country variables-on average.

\section{Conclusion}

This article has calculated a measure of global (industrialized) inflation (the first common factor) for CPI inflation, cyclical CPI inflation, core CPI inflation, and cyclical core CPI inflation. The first common factor is an important determinant of national inflation rates in industrial countries and in non-industrial and regional inflation rates. It is also generally helpful in forecasting U.S. inflation, but is less successful in helping to forecast other national inflation rates. In addition, the first common factor for cyclical inflation, and the second common factor for national inflation, are somewhat helpful in forecasting national inflation rates. In addition, the first four common factors are helpful in explaining national inflation rates in industrial countries, in non-industrial inflation and regional rates, and in food and energy inflation. Finally, the commonality of industrial inflation rates appears to reflect the commonality of macro variables that are determinants of inflation. 


\section{References}

[1] Ball, Laurence M. (2006), "Has Globalization Changed Inflation?" NBER Working Paper 12687.

[2] Borio, Claudio E. V. and Andrew Filardo (2007), "Globalisation and Inflation: New CrossCountry Evidence on the Global Determinants of Domestic Inflation," BIS Working Paper No. 227.

[3] Ciccarelli, Matteo, and Benoît Mojon (2005), "Global Inflation," European Central Bank Working Paper 537 .

[4] Corvoisier Sandrine and Benoît Mojon (2005), "Breaks in the Mean of Inflation: How They Happen and What to Do With Them," ECB Working Paper No. 451.

[5] Gavin, William T. and Kevin L. Kliesen (2008), "Forecasting Inflation and Output: Comparing Data-Rich Models with Simple Rules," Federal Reserve Bank of St. Louis Review, Volume 90, Number 3, pp. 175 - 192.

[6] Jackson, J. Edward (2003), A User's Guide to Principal Components, Hoboken: John Wiley \& Sons.

[7] Jolliffe, I.T. (2004), Principal Component Analysis, 2nd edition, New York: Springer.

[8] Kim, Jae-On, and Charles W. Mueller (1978), Introduction to Factor Analysis: What It Is and How To Do It, Newbury Park: Sage Publications.

[9] Kim, Jae-On, and Charles W. Mueller (1978), Factor Analysis: Statistical Methods and Practical Issues, Newbury Park: Sage Publications.

[10] Levin, Andrew T. and Jeremy M. Piger (2004), "Is Inflation Persistence Intrinsic in Industrial Economies?" ECB Working Paper No. 334.

[11] Rogoff, Kenneth S. (2003), "Globalization and Global Disinflation," in Monetary Policy and Uncertainty: Adapting to a Changing Economy, Federal Reserve Bank of Kansas City Jackson Hole Symposium.

[12] Stata Multivariate Statistics Reference Manual, Release 10 (2007), College Station: Stata Press.

[13] Stock, James H. and Mark W. Watson (2002), "Macroeconomic Forecasting Using Diffusion Indexes," Journal of Business \& Economic Statistics, 20: 147 - 162.

[14] Stock, James H. and Mark W. Watson (1999), "Forecasting Inflation," Journal of Monetary Economics, 44: 293 - 335.

[15] Theil, Henri (1971), Principles of Econometrics, New York: John Wiley and Sons. 
[16] White, William R. (2008), "Globalization and the Determinants of Domestic Inflation," BIS Working Paper, Bank for International Settlements. 
Table 1: CPI Inflation Rate

\begin{tabular}{lccccccc}
\hline \hline & F1 & F2 & Mean & Std Dev & Uniqueness & R2 & kmo \\
\hline Australia & 0.842 & -0.343 & 5.365 & 4.056 & 0.173 & 0.709 & 0.901 \\
Austria & 0.873 & 0.321 & 3.602 & 2.106 & 0.134 & 0.763 & 0.964 \\
Belgium & 0.921 & 0.098 & 3.853 & 2.932 & 0.143 & 0.848 & 0.927 \\
Canada & 0.901 & -0.244 & 4.253 & 3.177 & 0.129 & 0.812 & 0.922 \\
Finland & 0.920 & 0.029 & 5.407 & 4.388 & 0.152 & 0.847 & 0.954 \\
France & 0.940 & -0.116 & 4.872 & 3.777 & 0.104 & 0.883 & 0.923 \\
Germany & 0.788 & 0.445 & 2.923 & 1.806 & 0.181 & 0.622 & 0.881 \\
Italy & 0.916 & -0.224 & 6.907 & 5.681 & 0.111 & 0.839 & 0.930 \\
Japan & 0.766 & 0.416 & 3.687 & 4.379 & 0.240 & 0.587 & 0.904 \\
Korea & 0.641 & 0.243 & 9.349 & 7.714 & 0.531 & 0.410 & 0.906 \\
Luxembourg & 0.877 & 0.074 & 3.664 & 2.741 & 0.226 & 0.768 & 0.909 \\
Netherlands & 0.794 & 0.412 & 3.797 & 2.613 & 0.201 & 0.630 & 0.950 \\
New Zealand & 0.771 & -0.500 & 6.395 & 5.427 & 0.156 & 0.594 & 0.902 \\
Norway & 0.831 & -0.260 & 5.018 & 3.450 & 0.242 & 0.691 & 0.951 \\
Spain & 0.849 & -0.254 & 7.714 & 5.614 & 0.214 & 0.721 & 0.932 \\
Sweden & 0.858 & -0.174 & 5.148 & 3.699 & 0.234 & 0.736 & 0.944 \\
Switzerland & 0.689 & 0.504 & 3.013 & 2.351 & 0.272 & 0.474 & 0.843 \\
UK & 0.914 & -0.043 & 5.786 & 5.291 & 0.162 & 0.836 & 0.938 \\
US & 0.822 & -0.161 & 4.210 & 2.889 & 0.298 & 0.676 & 0.919 \\
&. &. &. &. &. &. &. \\
avg & 0.837 & 0.012 & 4.998 & 3.899 & 0.205 & 0.708 & 0.923 \\
std dev & 0.081 & 0.303 & 1.675 & 1.512 & 0.096 & 0.131 &. \\
min & 0.641 & -0.500 & 2.923 & 1.806 & 0.104 & 0.410 & 0.843 \\
max & 0.940 & 0.504 & 9.349 & 7.714 & 0.531 & 0.883 & 0.964 \\
\hline \hline
\end{tabular}


Table 2: Cyclical CPI Inflation Rate

\begin{tabular}{lccccccc}
\hline \hline & F1 & F2 & Mean & Std Dev & Uniqueness & R2 & kmo \\
\hline Australia & 0.530 & 0.468 & 0.000 & 1.713 & 0.500 & 0.281 & 0.758 \\
Austria & 0.659 & -0.275 & 0.000 & 1.017 & 0.490 & 0.435 & 0.899 \\
Belgium & 0.823 & -0.131 & -0.000 & 1.288 & 0.305 & 0.678 & 0.876 \\
Canada & 0.634 & 0.177 & 0.000 & 1.209 & 0.567 & 0.402 & 0.796 \\
Finland & 0.674 & 0.114 & -0.000 & 1.863 & 0.533 & 0.454 & 0.882 \\
France & 0.806 & -0.079 & -0.000 & 1.155 & 0.344 & 0.649 & 0.907 \\
Germany & 0.596 & -0.514 & -0.000 & 0.842 & 0.380 & 0.356 & 0.748 \\
Italy & 0.767 & 0.048 & -0.000 & 1.883 & 0.410 & 0.588 & 0.861 \\
Japan & 0.686 & -0.070 & 0.000 & 2.102 & 0.525 & 0.471 & 0.885 \\
Korea & 0.478 & 0.290 & -0.000 & 4.768 & 0.687 & 0.229 & 0.795 \\
Luxembourg & 0.679 & -0.241 & -0.000 & 1.248 & 0.481 & 0.460 & 0.774 \\
Netherlands & 0.607 & -0.242 & 0.000 & 1.104 & 0.573 & 0.368 & 0.797 \\
New Zealand & 0.250 & 0.685 & 0.000 & 2.285 & 0.468 & 0.063 & 0.580 \\
Norway & 0.392 & 0.444 & -0.000 & 1.645 & 0.649 & 0.154 & 0.677 \\
Spain & 0.137 & 0.088 & -0.000 & 1.834 & 0.974 & 0.019 & 0.522 \\
Sweden & 0.489 & 0.015 & 0.000 & 1.613 & 0.761 & 0.239 & 0.781 \\
Switzerland & 0.673 & -0.264 & -0.000 & 1.258 & 0.478 & 0.452 & 0.810 \\
UK & 0.642 & 0.213 & 0.000 & 2.237 & 0.543 & 0.412 & 0.849 \\
US & 0.662 & 0.122 & 0.000 & 1.356 & 0.547 & 0.439 & 0.812 \\
&. &. &. &. &. &. &. \\
avg & 0.589 & 0.045 & 0.000 & 1.706 & 0.538 & 0.376 & 0.819 \\
std dev & 0.177 & 0.298 & 0.000 & 0.852 & 0.154 & 0.178 &. \\
min & 0.137 & -0.514 & -0.000 & 0.842 & 0.305 & 0.019 & 0.522 \\
max & 0.823 & 0.685 & 0.000 & 4.768 & 0.974 & 0.678 & 0.907 \\
\hline \hline
\end{tabular}


Table 3: Core CPI Inflation Rate

\begin{tabular}{lccccccc}
\hline \hline & F1 & F2 & Mean & Std Dev & Uniqueness & R2 & kmo \\
\hline Australia & 0.771 & -0.535 & 4.967 & 3.481 & 0.120 & 0.594 & 0.849 \\
Austria & 0.893 & 0.276 & 3.819 & 2.372 & 0.127 & 0.797 & 0.926 \\
Belgium & 0.838 & 0.020 & 3.384 & 2.066 & 0.298 & 0.702 & 0.847 \\
Canada & 0.923 & -0.191 & 4.247 & 2.938 & 0.111 & 0.852 & 0.921 \\
Finland & 0.914 & -0.100 & 5.416 & 4.194 & 0.155 & 0.835 & 0.845 \\
France & 0.953 & -0.013 & 4.831 & 3.609 & 0.091 & 0.909 & 0.915 \\
Germany & 0.745 & 0.571 & 2.940 & 1.735 & 0.119 & 0.556 & 0.884 \\
Italy & 0.959 & 0.015 & 7.145 & 5.583 & 0.080 & 0.920 & 0.917 \\
Japan & 0.885 & 0.087 & 3.269 & 4.399 & 0.209 & 0.784 & 0.886 \\
Luxembourg & 0.865 & 0.272 & 3.945 & 2.640 & 0.179 & 0.748 & 0.905 \\
Netherlands & 0.726 & 0.480 & 3.905 & 2.590 & 0.243 & 0.527 & 0.908 \\
New Zealand & 0.776 & -0.516 & 7.258 & 5.861 & 0.132 & 0.602 & 0.860 \\
Norway & 0.887 & -0.321 & 4.195 & 3.415 & 0.110 & 0.787 & 0.852 \\
Spain & 0.973 & -0.047 & 7.725 & 6.195 & 0.052 & 0.946 & 0.930 \\
Sweden & 0.905 & 0.032 & 5.284 & 3.917 & 0.181 & 0.818 & 0.907 \\
Switzerland & 0.778 & 0.196 & 3.111 & 2.316 & 0.357 & 0.605 & 0.880 \\
UK & 0.848 & -0.115 & 6.299 & 5.604 & 0.268 & 0.718 & 0.910 \\
US & 0.901 & -0.025 & 4.155 & 2.662 & 0.188 & 0.812 & 0.909 \\
& $\cdot$ &. &. &. &. &. &. \\
avg & 0.863 & 0.005 & 4.772 & 3.643 & 0.168 & 0.751 & 0.892 \\
std dev & 0.076 & 0.294 & 1.480 & 1.396 & 0.081 & 0.129 & 0.893 \\
min & 0.726 & -0.535 & 2.940 & 1.735 & 0.052 & 0.527 &. \\
max & 0.973 & 0.571 & 7.725 & 6.195 & 0.357 & 0.946 & 0.930 \\
\hline \hline
\end{tabular}


Table 4: Cyclical Core CPI Inflation Rate

\begin{tabular}{lccccccc}
\hline \hline & F1 & F2 & Mean & Std Dev & Uniqueness & R2 & kmo \\
\hline Australia & 0.172 & 0.048 & 0.000 & 1.736 & 0.968 & 0.030 & 0.518 \\
Austria & 0.478 & 0.460 & -0.000 & 0.923 & 0.559 & 0.229 & 0.592 \\
Belgium & 0.081 & 0.838 & -0.000 & 0.803 & 0.291 & 0.006 & 0.625 \\
Canada & 0.585 & 0.005 & 0.000 & 1.126 & 0.658 & 0.342 & 0.745 \\
Finland & 0.354 & -0.060 & -0.000 & 1.802 & 0.871 & 0.125 & 0.356 \\
France & 0.750 & -0.148 & -0.000 & 1.059 & 0.416 & 0.563 & 0.775 \\
Germany & 0.658 & 0.299 & -0.000 & 0.783 & 0.477 & 0.433 & 0.757 \\
Italy & 0.713 & -0.282 & 0.000 & 1.661 & 0.412 & 0.508 & 0.796 \\
Japan & 0.308 & -0.143 & 0.000 & 1.684 & 0.885 & 0.095 & 0.452 \\
Luxembourg & 0.461 & 0.660 & 0.000 & 1.100 & 0.352 & 0.212 & 0.735 \\
Netherlands & 0.734 & 0.275 & -0.000 & 1.001 & 0.386 & 0.538 & 0.729 \\
New Zealand & 0.103 & -0.172 & -0.000 & 2.590 & 0.960 & 0.011 & 0.540 \\
Norway & 0.139 & 0.211 & -0.000 & 1.148 & 0.936 & 0.019 & 0.426 \\
Spain & 0.017 & 0.660 & -0.000 & 0.878 & 0.564 & 0.000 & 0.608 \\
Sweden & 0.565 & -0.335 & 0.000 & 1.495 & 0.569 & 0.319 & 0.619 \\
Switzerland & 0.683 & 0.345 & 0.000 & 1.052 & 0.414 & 0.467 & 0.773 \\
UK & 0.424 & -0.726 & -0.000 & 2.365 & 0.294 & 0.179 & 0.673 \\
US & 0.599 & -0.646 & 0.000 & 1.143 & 0.224 & 0.359 & 0.673 \\
&. &. &. &. &. &. &. \\
avg & 0.435 & 0.072 & 0.000 & 1.353 & 0.569 & 0.247 & 0.633 \\
std dev & 0.247 & 0.436 & 0.000 & 0.524 & 0.252 & 0.200 & 0.645 \\
min & 0.017 & -0.726 & -0.000 & 0.783 & 0.224 & 0.000 &. \\
max & 0.750 & 0.838 & 0.000 & 2.590 & 0.968 & 0.563 & 0.796 \\
\hline \hline
\end{tabular}


Table 5: ECM, Total CPI inflation

\begin{tabular}{lccccc}
\hline \hline & alpha & t-alpha & lambda1 & t-lambda1 & lambda0 \\
\hline Australia & -0.116 & -3.318 & -3.483 & -6.240 & -5.600 \\
Austria & -0.225 & -3.570 & -1.800 & -8.939 & -3.526 \\
Belgium & -0.170 & -3.717 & -2.421 & -9.382 & -4.060 \\
Canada & -0.128 & -3.195 & -2.937 & -9.458 & -4.370 \\
Finland & -0.183 & -4.107 & -4.000 & -12.842 & -5.471 \\
France & -0.053 & -1.672 & -4.093 & -11.691 & -4.741 \\
Germany & -0.100 & -2.847 & -1.242 & -4.586 & -2.976 \\
Italy & -0.090 & -3.626 & -6.439 & -10.341 & -6.966 \\
Japan & -0.075 & -2.202 & -2.947 & -4.175 & -3.199 \\
Korea & -0.184 & -4.409 & -3.749 & -3.389 & -9.386 \\
Luxembourg & -0.178 & -4.347 & -2.115 & -8.751 & -3.827 \\
Netherlands & -0.055 & -1.556 & -1.865 & -2.794 & -3.745 \\
New Zealand & -0.086 & -3.147 & -5.130 & -5.979 & -6.623 \\
Norway & -0.155 & -3.202 & -2.936 & -6.604 & -5.116 \\
Spain & -0.161 & -4.832 & -5.647 & -12.164 & -7.893 \\
Sweden & -0.140 & -3.357 & -3.672 & -8.649 & -5.121 \\
Switzerland & -0.089 & -2.844 & -1.256 & -2.995 & -2.984 \\
UK & -0.150 & -3.319 & -4.828 & -11.432 & -5.885 \\
US & -0.078 & -2.735 & -2.274 & -6.303 & -4.375 \\
\hline \hline
\end{tabular}


Table 6: ECM, Cyclical total CPI inflation

\begin{tabular}{lccccc}
\hline \hline & alpha & t-alpha & lambda1 & t-lambda1 & lambda0 \\
\hline Australia & -0.265 & -4.234 & -1.390 & -5.667 & -0.030 \\
Austria & -0.552 & -4.940 & -0.793 & -9.200 & 0.003 \\
Belgium & -0.194 & -3.233 & -1.785 & -12.419 & -0.053 \\
Canada & -0.250 & -3.520 & -1.024 & -7.752 & 0.014 \\
Finland & -0.350 & -5.346 & -1.501 & -8.114 & -0.033 \\
France & -0.202 & -5.064 & 0.108 & 0.481 & -0.020 \\
Germany & -0.006 & -0.108 & -1.130 & -7.637 & 0.021 \\
Italy & -0.545 & -5.778 & -1.406 & -12.749 & -0.047 \\
Japan & -0.420 & -5.765 & -0.641 & -2.910 & -0.017 \\
Korea & -0.442 & -7.468 & -0.265 & -0.484 & -0.166 \\
Luxembourg & -0.299 & -4.669 & -1.519 & -10.134 & -0.030 \\
Netherlands & -0.583 & -5.744 & -0.950 & -10.994 & -0.018 \\
New Zealand & -0.264 & -5.319 & 0.560 & 1.624 & -0.006 \\
Norway & -0.368 & -5.196 & -0.108 & -0.495 & -0.006 \\
Spain & -0.420 & -5.954 & -0.307 & -1.374 & -0.055 \\
Sweden & -0.373 & -5.154 & -0.873 & -4.413 & 0.009 \\
Switzerland & 0.055 & 1.233 & -1.905 & -7.924 & 0.014 \\
UK & -0.313 & -5.757 & -0.421 & -1.505 & 0.006 \\
US & -0.227 & -4.971 & 0.085 & 0.430 & -0.011 \\
\hline \hline
\end{tabular}


Table 7: ECM, Core CPI inflation

\begin{tabular}{lccccc}
\hline \hline & alpha & t-alpha & lambda1 & t-lambda1 & lambda0 \\
\hline Australia & -0.069 & -1.810 & -4.242 & -8.765 & -5.007 \\
Austria & -0.185 & -2.603 & -1.018 & -6.099 & -2.660 \\
Belgium & -0.258 & -5.048 & -1.926 & -11.239 & -3.063 \\
Canada & -0.162 & -2.782 & -2.989 & -12.045 & -3.779 \\
Finland & -0.066 & -1.237 & -3.575 & -15.107 & -3.466 \\
France & -0.060 & -3.577 & -1.262 & -2.312 & -2.299 \\
Germany & -0.064 & -2.289 & 0.128 & 0.285 & -2.007 \\
Italy & -0.062 & -3.130 & -2.662 & -3.828 & -4.333 \\
Japan & -0.043 & -1.279 & -2.215 & -7.718 & -0.991 \\
Luxembourg & -0.106 & -2.836 & -1.001 & -3.597 & -2.779 \\
Netherlands & -0.051 & -2.573 & 0.231 & 0.572 & -2.050 \\
New Zealand & -0.026 & -1.091 & -8.815 & -5.238 & -4.479 \\
Norway & -0.057 & -1.800 & -3.982 & -7.793 & -3.633 \\
Spain & -0.238 & -3.188 & -4.059 & -23.292 & -5.707 \\
Sweden & -0.018 & -0.395 & -4.875 & -9.261 & -2.323 \\
Switzerland & -0.017 & -1.686 & -5.098 & -5.904 & -4.770 \\
UK & 0.002 & 0.033 & -4.289 & -9.788 & -6.013 \\
US & -0.191 & -3.707 & -1.891 & -10.688 & -3.837 \\
\hline \hline
\end{tabular}


Table 8: ECM, Cyclical core CPI inflation

\begin{tabular}{lccccc}
\hline \hline & alpha & t-alpha & lambda1 & t-lambda1 & lambda0 \\
\hline Australia & -0.222 & -3.633 & -0.777 & -2.947 & -0.158 \\
Austria & 0.009 & 0.613 & 3.198 & 3.937 & 0.547 \\
Belgium & -0.409 & -5.854 & -0.408 & -3.650 & -0.074 \\
Canada & -0.306 & -4.107 & -0.607 & -3.619 & -0.071 \\
Finland & -0.102 & -1.555 & -0.850 & -4.262 & -0.100 \\
France & -0.464 & -4.309 & -0.537 & -8.485 & -0.052 \\
Germany & -0.482 & -5.059 & -0.405 & -4.552 & -0.033 \\
Italy & -0.306 & -3.606 & -0.716 & -6.315 & -0.099 \\
Japan & -0.247 & -3.702 & 0.188 & 1.474 & 0.033 \\
Luxembourg & -0.256 & -3.884 & -0.982 & -5.889 & -0.133 \\
Netherlands & -0.200 & -3.647 & -0.042 & -0.378 & 0.002 \\
New Zealand & -0.213 & -4.150 & 1.001 & 1.935 & 0.054 \\
Norway & -0.252 & -5.183 & 0.040 & 0.190 & 0.043 \\
Spain & -0.369 & -5.493 & 0.154 & 1.153 & 0.034 \\
Sweden & -0.215 & -1.981 & -0.966 & -6.191 & -0.039 \\
Switzerland & -0.252 & -5.046 & -0.802 & -7.413 & -0.145 \\
UK & -0.193 & -3.052 & -0.244 & -1.001 & 0.055 \\
US & -0.281 & -5.075 & 0.046 & 0.319 & 0.032 \\
\hline \hline
\end{tabular}

Table 9: ECM, Other CPI Inflation Rates

\begin{tabular}{lccccc}
\hline \hline & alpha & t alpha & lambda1 f1 & t f1 & lambda0 \\
\hline gp br & -0.279 & -3.630 & $-1.8 \mathrm{e}+03$ & -3.379 & $-1.9 \mathrm{e}+03$ \\
gp in & -0.144 & -4.333 & -0.490 & -0.547 & -7.888 \\
gp id & -0.215 & -5.074 & -1.999 & -1.393 & -12.660 \\
gp ru & -0.108 & -3.233 & 171.556 & 1.492 & 143.851 \\
pi4industrial & -0.073 & -1.273 & -3.185 & -20.159 & -4.802 \\
pi4euro & 0.120 & 0.669 & -4.964 & -6.684 & -6.425 \\
pi4devctyeur & -0.088 & -2.454 & 17.231 & 1.420 & -43.746 \\
pi4westhemis & -0.074 & -2.231 & 7.310 & 0.257 & -70.743 \\
pi4nonoildev & 0.001 & 2.028 & 839.658 & 2.490 & -60.498 \\
pi4emerdev & 0.005 & 1.046 & 46.654 & 2.095 & -24.659 \\
pi4mideast & -0.090 & -3.272 & -2.696 & -1.927 & -12.509 \\
pi4devasia & -0.103 & -3.354 & -2.524 & -3.271 & -7.620 \\
pi4africa & -0.021 & -1.237 & 4.417 & 0.993 & -17.585 \\
pi4opec & -0.072 & -2.383 & 1.126 & 0.665 & -13.173 \\
\hline \hline
\end{tabular}


Table 10: RMSE in Forecasting Total CPI Inflation

\begin{tabular}{|l|l|l|l|}
\hline & 1-step ahead & 4-steps ahead & 8-steps ahead \\
\hline RMSE for ECM & 0.438 & 1.169 & 1.090 \\
\hline RMSE for VAR with f1 & 0.436 & 1.165 & 1.098 \\
\hline RMSE, AR(2) & 0.470 & 1.142 & 1.465 \\
Relative to ECM & 1.073 & 0.977 & 1.345 \\
Relative to VAR & 1.080 & 0.980 & 1.335 \\
\hline RMSE, IMA(1,1) & 0.480 & 1.118 & 1.381 \\
Relative to ECM & 1.094 & 0.957 & 1.267 \\
Relative to VAR & 1.101 & 0.960 & 1.258 \\
\hline RMSE, RW & 0.447 & 1.047 & 1.254 \\
Relative to ECM & 1.019 & 0.896 & 1.151 \\
Relative to VAR & 1.026 & 0.899 & 1.143 \\
\hline RMSE, RW with drift & 0.449 & 1.072 & 1.324 \\
Relative to ECM & 1.024 & 0.917 & 1.215 \\
Relative to VAR & 1.031 & 0.920 & 1.206 \\
\hline * Rolling samples start with $1960 q 1-1989 q 4$. & \\
\hline
\end{tabular}


Table 11: RMSE in Forecasting Cyclical Total CPI Inflation

\begin{tabular}{|l|l|l|l|}
\hline & 1-step ahead & 4-steps ahead & 8-steps ahead \\
\hline RMSE for ECM & 0.408 & 0.855 & 0.542 \\
\hline RMSE for VAR with f1 & 0.399 & 0.803 & 0.556 \\
\hline RMSE, AR(2) & 0.438 & 0.778 & 0.657 \\
Relative to ECM & 1.073 & 0.911 & 1.212 \\
Relative to VAR & 1.097 & 0.969 & 1.180 \\
\hline RMSE, IMA(1,1) & 0.458 & 1.047 & 1.212 \\
Relative to ECM & 1.124 & 1.225 & 2.237 \\
Relative to VAR & 1.149 & 1.304 & 2.178 \\
\hline RMSE, RW & 0.437 & 0.994 & 1.114 \\
Relative to ECM & 1.070 & 1.164 & 2.056 \\
Relative to VAR & 1.094 & 1.239 & 2.002 \\
\hline RMSE, RW with drift & 0.438 & 1.008 & 1.144 \\
Relative to ECM & 1.074 & 1.179 & 2.111 \\
Relative to VAR & 1.098 & 1.255 & 2.056 \\
\hline * Rolling samples start with $1960 \mathrm{q} 1-1989 \mathrm{q} 4$. & \\
\hline
\end{tabular}

Table 12: RMSE in Forecasting Core CPI Inflation

\begin{tabular}{|l|l|l|l|}
\hline & 1-step ahead & 4-steps ahead & 8-steps ahead \\
\hline RMSE for ECM & 0.200 & 0.721 & 0.979 \\
\hline RMSE for VAR with f1 & 0.198 & 0.697 & 0.940 \\
\hline RMSE, AR(2) & 0.211 & 0.602 & 0.810 \\
Relative to ECM & 1.055 & 0.834 & 0.827 \\
Relative to VAR & 1.065 & 0.864 & 0.86 \\
\hline RMSE, IMA(1,1) & 0.221 & 0.731 & 1.130 \\
Relative to ECM & 1.103 & 1.014 & 1.154 \\
Relative to VAR & 1.115 & 1.050 & 1.202 \\
\hline RMSE, RW & 0.199 & 0.582 & 0.772 \\
Relative to ECM & 0.992 & 0.807 & 0.789 \\
Relative to VAR & 1.003 & 0.836 & 0.822 \\
\hline RMSE, RW with drift & 0.223 & 0.722 & 1.127 \\
Relative to ECM & 1.114 & 1.001 & 1.151 \\
Relative to VAR & 1.125 & 1.037 & 1.199 \\
\hline * Rolling samples start with $1980 \mathrm{q} 1-1999 \mathrm{q} 4$. & \\
\hline
\end{tabular}


Table 13: RMSE in Forecasting Cyclical Core CPI Inflation

\begin{tabular}{|l|l|l|l|}
\hline & 1-step ahead & 4-steps ahead & 8-steps ahead \\
\hline RMSE for ECM & 0.181 & 0.462 & 0.391 \\
\hline RMSE for VAR with f1 & 0.167 & 0.336 & 0.339 \\
\hline RMSE, AR(2) & 0.185 & 0.414 & 0.382 \\
Relative to ECM & 1.021 & 0.896 & 0.977 \\
Relative to VAR & 1.105 & 1.234 & 1.127 \\
\hline RMSE, IMA(1,1) & 0.193 & 0.547 & 0.689 \\
Relative to ECM & 1.070 & 1.184 & 1.761 \\
Relative to VAR & 1.158 & 1.630 & 2.032 \\
\hline RMSE, RW & 0.189 & 0.527 & 0.655 \\
Relative to ECM & 1.048 & 1.139 & 1.674 \\
Relative to VAR & 1.134 & 1.569 & 1.932 \\
\hline RMSE, RW with drift & 0.192 & 0.546 & 0.687 \\
Relative to ECM & 1.062 & 1.181 & 1.756 \\
Relative to VAR & 1.149 & 1.626 & 2.026 \\
\hline * Rolling samples start with $1980 q 1-1999 \mathrm{q} 4$. & \\
\hline
\end{tabular}


Table 14: How Many Models Beat the ECM or VAR for Overall CPI Inflation?

\begin{tabular}{|l|l|l|l|l|l|l|}
\hline \multicolumn{1}{|c|}{ Country } & \multicolumn{3}{c|}{ ECM } & \multicolumn{3}{c|}{ VAR } \\
\hline & 1 -step & 4 -steps & 8 -steps & 1-step & 4 -step & 8 -step \\
\hline Australia & 0 & 1 & 0 & 0 & 0 & 0 \\
\hline Austria & 4 & 0 & 0 & 4 & 3 & 0 \\
\hline Belgium & 2 & 3 & 2 & 2 & 3 & 3 \\
\hline Canada & 0 & 0 & 0 & 0 & 0 & 1 \\
\hline Finland & 3 & 3 & 3 & 4 & 4 & 4 \\
\hline France & 2 & 3 & 3 & 2 & 3 & 3 \\
\hline Germany & 0 & 3 & 0 & 0 & 4 & 4 \\
\hline Italy & 4 & 3 & 3 & 4 & 3 & 1 \\
\hline Japan & 4 & 3 & 3 & 4 & 4 & 3 \\
\hline Korea & 4 & 4 & 4 & 4 & 4 & 4 \\
\hline Luxembourg & 2 & 3 & 2 & 2 & 3 & 2 \\
\hline Netherlands & 4 & 4 & 4 & 2 & 4 & 4 \\
\hline New Zealand & 0 & 3 & 3 & 0 & 3 & 3 \\
\hline Norway & 0 & 3 & 3 & 0 & 3 & 3 \\
\hline Spain & 3 & 3 & 3 & 3 & 3 & 3 \\
\hline Sweden & 0 & 0 & 0 & 0 & 0 & 0 \\
\hline Switzerland & 1 & 3 & 3 & 3 & 4 & 4 \\
\hline United Kingdom & 3 & 3 & 1 & 2 & 3 & 3 \\
\hline United States & 0 & 4 & 0 & 0 & 4 & 0 \\
\hline
\end{tabular}


Table 15: How Many Models Beat the ECM or VAR for Cyclical CPI Inflation?

\begin{tabular}{|l|l|l|l|l|l|l|}
\hline \multicolumn{1}{|c|}{ Country } & \multicolumn{3}{|c|}{ ECM } & \multicolumn{3}{c|}{ VAR } \\
\hline & 1 -step & 4 -steps & 8-steps & 1-step & 4-step & 8-step \\
\hline Australia & 0 & 1 & 1 & 0 & 1 & 0 \\
\hline Austria & 4 & 1 & 1 & 4 & 1 & 1 \\
\hline Belgium & 3 & 4 & 3 & 2 & 1 & 1 \\
\hline Canada & 0 & 1 & 1 & 0 & 0 & 0 \\
\hline Finland & 4 & 4 & 4 & 3 & 1 & 0 \\
\hline France & 2 & 1 & 1 & 2 & 1 & 1 \\
\hline Germany & 1 & 4 & 4 & 0 & 1 & 1 \\
\hline Italy & 4 & 4 & 4 & 4 & 4 & 1 \\
\hline Japan & 4 & 4 & 1 & 4 & 4 & 1 \\
\hline Korea & 1 & 0 & 1 & 1 & 0 & 1 \\
\hline Luxembourg & 3 & 4 & 4 & 0 & 1 & 1 \\
\hline Netherlands & 0 & 0 & 1 & 0 & 0 & 0 \\
\hline New Zealand & 0 & 0 & 0 & 0 & 1 & 0 \\
\hline Norway & 0 & 1 & 1 & 0 & 1 & 1 \\
\hline Spain & 4 & 1 & 1 & 4 & 1 & 1 \\
\hline Sweden & 0 & 1 & 1 & 0 & 0 & 1 \\
\hline Switzerland & 1 & 4 & 2 & 1 & 1 & 1 \\
\hline United Kingdom & 3 & 1 & 1 & 3 & 1 & 1 \\
\hline United States & 0 & 1 & 0 & 0 & 1 & 0 \\
\hline
\end{tabular}


Table 16: How Many Models Beat the ECM or VAR for Core CPI Inflation?

\begin{tabular}{|l|l|l|l|l|l|l|}
\hline \multicolumn{1}{|c|}{ Country } & \multicolumn{3}{c|}{ ECM } & \multicolumn{3}{c|}{ VAR } \\
\hline & 1 -step & 4 -steps & 8 -steps & 1 -step & 4 -step & 8 -step \\
\hline Australia & 4 & 4 & 4 & 3 & 4 & 0 \\
\hline Austria & 0 & 0 & 0 & 0 & 0 & 0 \\
\hline Belgium & 1 & 0 & 4 & 1 & 0 & 4 \\
\hline Canada & 2 & 4 & 4 & 1 & 0 & 0 \\
\hline Finland & 4 & 4 & 0 & 1 & 0 & 0 \\
\hline France & 0 & 2 & 2 & 0 & 2 & 2 \\
\hline Germany & 3 & 4 & 4 & 2 & 4 & 3 \\
\hline Italy & 2 & 2 & 0 & 2 & 2 & 0 \\
\hline Japan & 4 & 4 & 3 & 4 & 4 & 2 \\
\hline Korea & & & & & & \\
\hline Luxembourg & 4 & 4 & 3 & 4 & 4 & 4 \\
\hline Netherlands & 1 & 3 & 3 & 0 & 3 & 2 \\
\hline New Zealand & 4 & 4 & 4 & 4 & 1 & 1 \\
\hline Norway & 3 & 4 & 4 & 3 & 2 & 0 \\
\hline Spain & 2 & 3 & 2 & 0 & 1 & 1 \\
\hline Sweden & 3 & 4 & 4 & 0 & 0 & 0 \\
\hline Switzerland & 2 & 3 & 3 & 2 & 3 & 3 \\
\hline United Kingdom & 4 & 4 & 4 & 4 & 1 & 1 \\
\hline United States & 1 & 2 & 2 & 0 & 2 & 2 \\
\hline
\end{tabular}


Table 17: How Many Models Beat the ECM or VAR for Cyclical Core CPI Inflation?

\begin{tabular}{|l|l|l|l|l|l|l|}
\hline \multicolumn{1}{|c|}{ Country } & \multicolumn{3}{c|}{ ECM } & \multicolumn{3}{c|}{ VAR } \\
\hline & 1 -step & 4 -steps & 8 -steps & 1 -step & 4 -step & 8 -step \\
\hline Australia & 3 & 3 & 1 & 3 & 3 & 1 \\
\hline Austria & 4 & 4 & 2 & 1 & 1 & 1 \\
\hline Belgium & 0 & 0 & 2 & 0 & 0 & 2 \\
\hline Canada & 0 & 0 & 1 & 0 & 0 & 0 \\
\hline Finland & 4 & 4 & 1 & 4 & 2 & 0 \\
\hline France & 0 & 0 & 1 & 0 & 0 & 1 \\
\hline Germany & 0 & 0 & 1 & 0 & 0 & 1 \\
\hline Italy & 4 & 4 & 3 & 4 & 3 & 1 \\
\hline Japan & 3 & 1 & 0 & 4 & 1 & 0 \\
\hline Korea & & & & & & \\
\hline Luxembourg & 4 & 4 & 4 & 4 & 4 & 1 \\
\hline Netherlands & 1 & 1 & 1 & 1 & 1 & 1 \\
\hline New Zealand & 3 & 3 & 1 & 3 & 1 & 1 \\
\hline Norway & 0 & 0 & 0 & 0 & 0 & 0 \\
\hline Spain & 2 & 1 & 1 & 2 & 1 & 1 \\
\hline Sweden & 4 & 3 & 1 & 4 & 1 & 1 \\
\hline Switzerland & 2 & 4 & 4 & 2 & 4 & 1 \\
\hline United Kingdom & 2 & 1 & 2 & 4 & 4 & 2 \\
\hline United States & 0 & 1 & 1 & 0 & 0 & 0 \\
\hline
\end{tabular}


Table 18: Does Adding the First Factor for Cyclical Inflation Help to Forecast Inflation?

\begin{tabular}{|c|c|c|c|c|c|c|}
\hline \multirow[t]{2}{*}{ Country } & \multicolumn{3}{|c|}{ ECM } & \multicolumn{3}{|c|}{ VAR } \\
\hline & 1-step & 4-steps & 8-steps & 1-step & 4-step & 8-step \\
\hline \multicolumn{7}{|l|}{ Australia } \\
\hline Austria & $\mathrm{Y}$ & & & $\mathrm{Y}$ & $\mathrm{Y}$ & $\mathrm{Y}$ \\
\hline \multicolumn{7}{|l|}{ Belgium } \\
\hline \multicolumn{7}{|l|}{ Canada } \\
\hline Finland & $\mathrm{Y}$ & $\mathrm{Y}$ & $\mathrm{Y}$ & & $\mathrm{Y}$ & $\mathrm{Y}$ \\
\hline France & $\mathrm{Y}$ & $\mathrm{Y}$ & & $\mathrm{Y}$ & $\mathrm{Y}$ & \\
\hline Germany & & & & $\mathrm{Y}$ & $\mathrm{Y}$ & $\mathrm{Y}$ \\
\hline Italy & $\mathrm{Y}$ & $\mathrm{Y}$ & & & & \\
\hline Japan & $\mathrm{Y}$ & & & $\mathrm{Y}$ & $\mathrm{Y}$ & $\mathrm{Y}$ \\
\hline Korea & $\mathrm{Y}$ & $\mathrm{Y}$ & $\mathrm{Y}$ & $\mathrm{Y}$ & $\mathrm{Y}$ & $\mathrm{Y}$ \\
\hline Luxembourg & & & & $\mathrm{Y}$ & $\mathrm{Y}$ & $\mathrm{Y}$ \\
\hline Netherlands & $\mathrm{Y}$ & $\mathrm{Y}$ & $\mathrm{Y}$ & $\mathrm{Y}$ & $\mathrm{Y}$ & $\mathrm{Y}$ \\
\hline New Zealand & $\mathrm{Y}$ & $\mathrm{Y}$ & $\mathrm{Y}$ & $\mathrm{Y}$ & $\mathrm{Y}$ & $\mathrm{Y}$ \\
\hline Norway & $\mathrm{Y}$ & $\mathrm{Y}$ & $\mathrm{Y}$ & $\mathrm{Y}$ & $\mathrm{Y}$ & $\mathrm{Y}$ \\
\hline \multicolumn{7}{|l|}{ Spain } \\
\hline Sweden & $\mathrm{Y}$ & & & & & $\mathrm{Y}$ \\
\hline Switzerland & & & & $\mathrm{Y}$ & $\mathrm{Y}$ & $\mathrm{Y}$ \\
\hline United Kingdom & $\mathrm{Y}$ & $\mathrm{Y}$ & & & & $\mathrm{Y}$ \\
\hline United States & & & & & & \\
\hline
\end{tabular}


Table 19: Does adding the second common factor help predict CPI inflation?

\begin{tabular}{|l|l|l|l|l|l|l|}
\hline \multicolumn{1}{|c|}{ Country } & \multicolumn{3}{c|}{ ECM } & \multicolumn{3}{c|}{ VAR } \\
\hline & 1-step & 4-steps & 8-steps & 1-step & 4-step & 8-step \\
\hline Australia & & & & & & \\
\hline Austria & Y & Y & & Y & Y & \\
\hline Belgium & & & & & & \\
\hline Canada & & Y & & & Y & Y \\
\hline Finland & & & & & & \\
\hline France & & & & & & \\
\hline Germany & & & & Y & Y & \\
\hline Italy & $\mathrm{Y}$ & $\mathrm{Y}$ & & & & \\
\hline Japan & & & & & & \\
\hline Korea & $\mathrm{Y}$ & $\mathrm{Y}$ & $\mathrm{Y}$ & $\mathrm{Y}$ & $\mathrm{Y}$ & $\mathrm{Y}$ \\
\hline Luxembourg & & & & & & \\
\hline Netherlands & & $\mathrm{Y}$ & $\mathrm{Y}$ & & $\mathrm{Y}$ & \\
\hline New Zealand & & & & & & \\
\hline Norway & $\mathrm{Y}$ & $\mathrm{Y}$ & $\mathrm{Y}$ & & & \\
\hline Spain & & & & & & \\
\hline Sweden & & & $\mathrm{Y}$ & & & \\
\hline Switzerland & $\mathrm{Y}$ & $\mathrm{Y}$ & $\mathrm{Y}$ & & & \\
\hline United Kingdom & & & & & & \\
\hline United States & & & & & & $\mathrm{Y}$ \\
\hline
\end{tabular}


Table 20: Additional Common Factors, t-statistic on sum of lags 1 to 4

\begin{tabular}{lccccc}
\hline \hline & gp & F1 & F2 & F3 & F4 \\
\hline Australia & 13.495 & 3.599 & -1.581 & -0.874 & -0.100 \\
Austria & 3.390 & 5.756 & 4.623 & -1.508 & 0.211 \\
Belgium & 7.841 & 4.676 & 2.305 & -2.840 & -2.117 \\
Canada & 12.950 & 3.719 & -2.364 & 0.324 & 0.184 \\
Finland & 14.704 & 3.671 & 0.716 & -0.339 & -0.793 \\
France & 23.699 & 1.871 & -0.030 & 0.230 & 0.639 \\
Germany & 11.797 & 1.761 & 1.304 & 1.520 & 1.462 \\
Italy & 19.783 & 3.822 & -1.451 & -0.474 & 0.328 \\
Japan & 12.605 & 3.620 & 3.703 & 0.080 & -0.660 \\
Korea & 2.365 & 4.222 & 3.868 & 3.462 & 1.260 \\
Luxembourg & 12.191 & 3.364 & 1.604 & -0.386 & 0.449 \\
Netherlands & 10.214 & 3.512 & 3.534 & 1.948 & -1.192 \\
New Zealand & 15.377 & 3.457 & -1.657 & 0.552 & 0.176 \\
Norway & 11.106 & 4.754 & -2.292 & 0.882 & 0.666 \\
Spain & 15.490 & 4.501 & -1.309 & 0.754 & -2.668 \\
Sweden & 10.907 & 5.162 & -2.409 & -1.222 & 0.506 \\
Switzerland & 9.684 & 1.445 & 1.025 & -0.044 & 1.536 \\
UK & 17.128 & 3.652 & -0.146 & 1.593 & -0.232 \\
US & 22.531 & 1.673 & -0.969 & 0.319 & -0.220 \\
\hline \hline
\end{tabular}


Table 21: Additional Common Factors, t-statistic on sum of lags 5 to 8

\begin{tabular}{lccccc}
\hline \hline & gp & F1 & F2 & F3 & F4 \\
\hline Australia & 1.074 & 4.923 & -0.795 & -1.283 & 0.036 \\
Austria & -3.232 & 7.317 & 6.347 & -1.608 & 1.287 \\
Belgium & -3.000 & 7.456 & 4.573 & -3.402 & -1.333 \\
Canada & 0.033 & 5.884 & -3.611 & 1.374 & -0.440 \\
Finland & 1.034 & 4.252 & 2.084 & -0.526 & 1.421 \\
France & 3.898 & 3.304 & -0.100 & 1.104 & 0.850 \\
Germany & 1.948 & 2.590 & 1.348 & 4.021 & 2.756 \\
Italy & 1.466 & 5.760 & -0.661 & -0.014 & 1.591 \\
Japan & 1.483 & 2.951 & 4.294 & -0.009 & -0.169 \\
Korea & -3.953 & 6.480 & 5.447 & 5.478 & -0.016 \\
Luxembourg & -0.358 & 6.783 & 2.911 & -0.081 & 2.024 \\
Netherlands & 5.668 & 0.363 & 1.744 & 3.823 & 1.745 \\
New Zealand & 1.992 & 4.869 & -0.910 & -0.111 & -1.576 \\
Norway & 1.421 & 5.923 & -2.006 & 3.071 & 1.398 \\
Spain & 1.086 & 9.268 & 0.883 & 1.899 & -4.862 \\
Sweden & 0.607 & 5.921 & -4.627 & 1.962 & -1.141 \\
Switzerland & 2.260 & 0.804 & 0.304 & 2.228 & 1.426 \\
UK & 0.962 & 5.314 & 0.917 & -0.129 & -1.305 \\
US & 2.724 & 3.763 & -0.811 & 1.336 & 0.193 \\
\hline \hline
\end{tabular}


Table 22: Additional Common Factors, t-statistic on sum of lags 8 to 11

\begin{tabular}{lccccc}
\hline \hline & gp & F1 & F2 & F3 & F4 \\
\hline Australia & -0.276 & 5.129 & -0.615 & -1.935 & -0.802 \\
Austria & -1.521 & 4.180 & 3.919 & 0.191 & 2.598 \\
Belgium & -4.296 & 7.306 & 4.963 & -2.124 & -0.848 \\
Canada & -1.728 & 6.120 & -3.217 & 1.817 & -1.161 \\
Finland & -0.481 & 4.485 & 3.001 & -0.105 & 0.436 \\
France & 1.293 & 4.381 & 0.463 & 2.397 & 0.574 \\
Germany & 0.638 & 2.220 & 0.912 & 3.893 & 2.520 \\
Italy & -1.483 & 7.502 & -1.930 & 0.300 & 0.678 \\
Japan & 2.017 & 1.165 & 2.755 & -0.276 & 0.586 \\
Korea & -3.576 & 5.394 & 5.234 & 4.319 & -0.824 \\
Luxembourg & -2.639 & 7.152 & 2.441 & 0.049 & 1.604 \\
Netherlands & 6.793 & -2.687 & 0.007 & 3.327 & 3.834 \\
New Zealand & 3.135 & 4.204 & 1.248 & -3.190 & -3.698 \\
Norway & 3.012 & 3.231 & 0.689 & 2.735 & 1.360 \\
Spain & 0.796 & 8.395 & 2.234 & 1.785 & -2.861 \\
Sweden & -2.125 & 7.647 & -3.568 & 3.100 & 1.248 \\
Switzerland & 3.031 & -0.991 & -1.816 & 4.496 & -0.620 \\
UK & 0.588 & 3.742 & 2.436 & -1.956 & -0.611 \\
US & -0.910 & 5.449 & -1.020 & 2.019 & 0.175 \\
\hline \hline
\end{tabular}

Table 23: Additional Common Factors, t-statistic on sum of lags 1 to 4

\begin{tabular}{lccccc}
\hline \hline & gp & F1 & F2 & F3 & F4 \\
\hline pi4nonoildev & 34.494 & 1.265 & -1.355 & -2.047 & 1.288 \\
pi4emerdev & 39.626 & 1.165 & -1.191 & -1.912 & 1.220 \\
pi4devasia & 24.461 & 2.153 & 1.253 & -1.729 & 2.195 \\
pi4opec & 26.511 & -0.500 & 0.361 & 0.503 & 0.700 \\
pi4food & 10.531 & 0.588 & 0.982 & -1.830 & -0.669 \\
pi4energy & 1.556 & -2.842 & -0.379 & -3.589 & 1.515 \\
\hline \hline
\end{tabular}


Table 24: Additional Common Factors, t-statistic on sum of lags 5 to 8

\begin{tabular}{lccccc}
\hline \hline & gp & F1 & F2 & F3 & F4 \\
\hline pi4nonoildev & 6.818 & 3.834 & -3.057 & -2.774 & 4.360 \\
pi4emerdev & 7.380 & 3.526 & -2.646 & -2.626 & 4.528 \\
pi4devasia & 0.207 & 3.915 & 2.887 & -1.660 & 3.364 \\
pi4opec & 4.322 & -0.490 & 1.809 & -0.599 & 3.368 \\
pi4food & -0.792 & 0.258 & 2.085 & -1.217 & -0.088 \\
pi4energy & -1.787 & -1.512 & -1.760 & -1.051 & 0.192 \\
\hline \hline
\end{tabular}

Table 25: Additional Common Factors, t-statistic on sum of lags 8 to 11

\begin{tabular}{lccccc}
\hline \hline & gp & F1 & F2 & F3 & F4 \\
\hline pi4nonoildev & 5.819 & 6.641 & -4.827 & -2.310 & 6.006 \\
pi4emerdev & 6.012 & 6.218 & -4.346 & -2.352 & 6.358 \\
pi4devasia & -3.144 & 5.442 & 3.912 & 0.170 & 4.618 \\
pi4opec & 3.722 & -0.477 & 2.562 & -1.775 & 5.539 \\
pi4food & -1.539 & 0.263 & 1.295 & 0.282 & -0.648 \\
pi4energy & 0.367 & -5.834 & 2.486 & -3.167 & -2.065 \\
\hline \hline
\end{tabular}

Table 26: Commonality of business cycle variables

\begin{tabular}{|c|c|c|c|c|c|}
\hline \multirow{2}{*}{ Variable } & Number & \multicolumn{4}{|c|}{ Uniqueness } \\
\cline { 3 - 6 } of countries & & \multicolumn{1}{|c|}{$\mathbf{1}$ factor } & \multicolumn{2}{|c|}{$\mathbf{3}$ factors } \\
\cline { 3 - 6 } & & avg & max & avg & max \\
\hline Cyclical unemployment & 13 & .58 & .93 & .33 & .91 \\
Cyclical real GDP & 9 & .58 & .72 & .26 & .41 \\
Real GDP growth & 9 & .40 & .79 & .17 & .25 \\
Narrow money growth & 6 & .71 & .99 & .26 & .41 \\
Broad money growth & 6 & .40 & .77 & .13 & .24 \\
Short-term interest rate & 7 & .19 & .35 & .06 & .10 \\
Intermediate interest rate & 5 & .27 & .45 & .03 & .08 \\
Long-term interest rate & 6 & .19 & .59 & .03 & .06 \\
\hline
\end{tabular}

